\title{
Knowledge, awareness and practice of vitamin D among population of Qassim Region, Saudi Arabia before and during COVID-19 pandemic
}

\author{
*Alhomaid, R.M. \\ Department of Food Science and Human Nutrition, College of Agriculture and Veterinary Medicine, Qassim \\ University, Buraydah, Saudi Arabia
}

\section{Article history:}

Received: 4 April 2021

Received in revised form: 8

May 2021

Accepted: 10 June 2021

Available Online: 7

November 2021

\section{Keywords:}

Vitamin D,

COVID-19 pandemic,

Knowledge,

Awareness,

Sun,

Exposure

DOI:

https://doi.org/10.26656/fr.2017.5(6).237

\begin{abstract}
One billion people globally have been affected by vitamin D deficiency and its associated diseases; therefore, the present study was aimed to estimate the knowledge, awareness and practices of vitamin $\mathrm{D}$ in the Qassim region of the adult population before and during the COVID-19 pandemic. A cross-sectional survey was conducted among 195 of the general adult population in the Qassim region, Saudi Arabia from $15^{\text {th }}$ September 2020 to $25^{\text {th }}$ October 2020. The results revealed that a high percentage of participants are cognizant of vitamin D (93.8\%). Also, it appears that there was no association between knowledge and awareness of vitamin D and age, gender, education or social status. Around $82.6 \%$ of the participants know the sources of vitamin D and the majority of participants enjoy sun exposure (79\%), where the most time exposed to the sun is early in the morning and after $3 \mathrm{pm}$, reported to at $43.6 \%$ and $52.3 \%$, respectively. In addition, about $35 \%$ of participants increased their knowledge of vitamin D after the emergence of COVID-19. A high percentage of participants thought that vitamin D raising the body immunity against viral infection or improve immunity, in general, was at $67.7 \%$, that thought that vitamin D prevents or increase resistance to COVID-19. From the foregoing results, it could be concluded that a high level of knowledge and awareness about vitamin D in adults living in the Qassim region and increased knowledge after the emergence of COVID-19 is the most important result of the current study.
\end{abstract}

\section{Introduction}

Vitamin D is considered an immunomodulatory agent and has hormonal action related to the maintenance of mineral and skeletal homeostasis is essential for maintaining a healthy skeleton. The main function of vitamin $\mathrm{D}$ is to regulate the metabolism of calcium and phosphate in the body (Holick, 2007; Prietl et al., 2013).

The primary source of vitamin D in the human body is from the exposure of skin to ultraviolet light which represents more than $90 \%$ of vitamin D needed for humans. The 7-dehydrocholesterol under the skin is converted to ultraviolet light band B (UVB) to an inactive precursor vitamin D3 (cholecalciferol). The remaining need for vitamin $\mathrm{D}(10 \%)$ is gained from different food sources rich in vitamin D (Holick, 2004). However, many factors can affect the synthesis of vitamin D for UVB under the skin such as latitude, pollution, solar zenith angles, ozone layer and pigmentation (Holick, 2007).

Vitamin D deficiency is a global public health problem. Around 1 billion people worldwide suffer from vitamin D deficiency (Bjorklund, 2016). In this regard, Vitamin D deficiency is common in the Saudi Arabia population (Kelishadi, 2014; Green et al., 2015). The experts work in Prince Mutaib Chair for Biomarkers of Osteoporosis task force in Saudi Arabia have been defined the sufficient level of vitamin $\mathrm{D}$ as circulating serum $25(\mathrm{OH})$ D $(\geq 50 \mathrm{nmol}$ or $\geq 20 \mathrm{ng} / \mathrm{mL})$ for the general population (Al-Daghri, 2018), similarly to the IOM, USA that the recommended cut-off of vitamin D status $25(\mathrm{OH}) \mathrm{D}$ is $(20 \mathrm{ng} / \mathrm{mL}$ or $50 \mathrm{nmol} / \mathrm{L})$ for normal healthy people as the main basis of bone health.

In recent years many studies have reported that vitamin D deficiency has been found to be significantly associated with common chronic diseases such as cardiovascular diseases, cancer, diabetes and immune system diseases (Wang, 2017). In addition, it has been reported that vitamin $\mathrm{D}$ is involved in regulating immune function, inhibiting inflammatory reactions, autoimmune diseases as well as immune cell biology system (Moreira and Hamadeh, 2010; Jeffery et al., 2015). 
The lack of knowledge and practice of vitamins in addition to the wrong lifestyle, indoor activity, extensive cloths cover as well as lack of regular exposure to sunlight can be considered the major cause of Vitamin D deficiency among the Saudi population. Thus, the increase in knowledge, awareness and importance of effective practices about vitamin D is important for the general population to know. Its benefit on health especially on the prevention of diseases related to deficiency and insufficiency. Therefore, the primary goal of this study was to investigate the amount of knowledge, awareness and practices about vitamin D of adults living in the Qassim region before and during the emergence of the COVID-19 pandemic.

\section{Methodology}

\subsection{Questionnaire}

For data collection, a cross-sectional survey was conducted among the general adult population in the Qassim region, Saudi Arabia from $15^{\text {th }}$ September 2020 to $25^{\text {th }}$ October 2020. An electronic self-administered questionnaire (Google form) consisting of five parts was used to collect data (socio-demographic characters, health and anthropometric data, knowledge and awareness of vitamin $\mathrm{D}$, attitude and practices of an individual about vitamin $\mathrm{D}$ and sun exposure and awareness associated after COVID-19 pandemic). The questionnaire was designed by the author and validated by three arbitrators in the study area. The questionnaire was previously tested for reliability and accuracy among twenty participants.

\subsection{Statistical analysis}

Data were statistically analysed using descriptive statistics using IBM SPSS statistics for mac version 25.0 (SPSS Inc., Chicago, IL). Descriptive statistics were used to characterize the participants of the study population. Data were presented as a percentage in frequency tables for each part of the questionnaire to identify the participant's Socio-demographic characters information, knowledge and awareness of vitamin $\mathrm{D}$, sun exposure and practices about vitamin D and after the emergence of COVID-19. A Chi-square test was conducted to identify the association between knowledge and awareness of vitamin D and each of age, gender, education and social status, at the significance level of $\mathrm{p} \leq 0.05$.

\subsection{Ethics statement}

The questionnaire and data collection, a crosssectional survey was approved by the Ethics Committee of Health Research Ethics, Deanship of Scientific Research, Qassim University, 20-06-13.

\section{Results}

\subsection{Socio-demographic characters information}

One hundred and ninety-five participates have completed the survey. Table 1 shows the Sociodemographic characteristics, the ages of participants where $59 \%$ were between $18-35$ years, $33.8 \%$ between $36-50$ years and $7.2 \%$ over 50 years. Most of the participants were male $(61.5 \%)$, different education levels were found in this survey where most of them held a bachelor's degree (72.8\%). In this survey, almost half of the participants were students $(55.5 \%)$ and $63.1 \%$ of participants were unmarried. Regarding health, most of the participants were not diagnosed with any chronic disease $(83.6 \%)$.

Table 1. Socio-demographic characters information

\begin{tabular}{lcc}
\hline Question & Mean & SD \\
\hline Weight $(\mathrm{Kg})$ & 69.9 & 23.4 \\
Hight $(\mathrm{cm})$ & 162.3 & 15.9 \\
\hline \multicolumn{1}{|c}{ Age (year) } & $\mathrm{N}$ & \\
\hline $18-35$ & 115 & 59 \\
$36-50$ & 66 & 33.8 \\
$>50$ & 14 & 7.2 \\
\hline Gender & & \\
\hline Male & 120 & 61.5 \\
Female & 75 & 38.5 \\
Education & & \\
High school & 24 & 12.3 \\
Diploma & 18 & 9.2 \\
Bachelor degree & 142 & 72.8 \\
Higher degree & 11 & 5.6 \\
\hline Job & & \\
\hline Unemployed & 37 & 19 \\
Free business & 6 & 3.1 \\
Housewife & 1 & 0.5 \\
Student & 108 & 55.4 \\
Retired & 8 & 4.1 \\
Teacher & 2 & 1 \\
Government employee & 23 & 11.8 \\
Private employee & 10 & 5.1 \\
\hline Social status & & \\
\hline Wido/widower & 1 & 0.5 \\
Unmarried & 123 & 63.1 \\
Married & 67 & 34.4 \\
Separated & 4 & 2.1 \\
\hline Have you been diagnosed with a chronic disease? & \\
\hline Yes & 32 & 16.4 \\
No & 163 & 83.6 \\
\hline
\end{tabular}

\subsection{Knowledge and awareness of vitamin D}

Data presented in Table 2 depicts the knowledge and awareness of vitamin D. Most of the participants (93.8\%) were aware that vitamin D is essential for health. There was no significant association between knowledge and awareness of vitamin D in age, gender, education and social status. About $82.6 \%$ of the participants understood 
Table 2. Knowledge and awareness of vitamin D

\begin{tabular}{|c|c|c|}
\hline Question & $\mathrm{N}$ & $\%$ \\
\hline \multicolumn{3}{|c|}{ Do you know about vitamin D? } \\
\hline Yes & 183 & 93.8 \\
\hline No & 12 & 6.2 \\
\hline \multicolumn{3}{|c|}{ Is the vitamin $\mathrm{D}$ in the body? } \\
\hline Yes & 159 & 81.5 \\
\hline No & 36 & 18.5 \\
\hline \multicolumn{3}{|l|}{ Sources of vitamin D: } \\
\hline Sun light & 28 & 14.4 \\
\hline vitamins Supplement & 3 & 1.5 \\
\hline Some foods & 1 & 0.5 \\
\hline All the above & 161 & 82.6 \\
\hline I do not know & 2 & 1 \\
\hline \multicolumn{3}{|c|}{ Dose vitamin D effect on health: } \\
\hline Good & 148 & 75.9 \\
\hline Bad & 32 & 16.4 \\
\hline I do not know & 15 & 7.7 \\
\hline \multicolumn{3}{|c|}{ Do you know is vitamin D good for bone health? } \\
\hline Yes & 176 & 90.3 \\
\hline No & 3 & 1.5 \\
\hline I do not know & 16 & 8.2 \\
\hline \multicolumn{3}{|c|}{ Is vitamin D deficiency related to muscle pain? } \\
\hline Yes & 133 & 68.2 \\
\hline No & 12 & 6.2 \\
\hline I do not know & 50 & 25.6 \\
\hline
\end{tabular}

Do you think that vitamin D deficiency has related to other health conditions in the body such as heart disease/diabetes/

\begin{tabular}{lcc}
\hline Yes & 50.8 & 99 \\
No & 24 & 12.3 \\
I do not know & 36.9 & 72 \\
\hline Sources of knowledge about vitamin D? & 3 & 1.5 \\
\hline Newspapers and magazines & 8.2 \\
TV and radio & 49.7 \\
Friends and relatives & 53.3 \\
Social Media & 47.2 \\
Doctors in net and social sites & 104 \\
Doctors in clinics and hospitals & 92 \\
Health Publications, Brochures & 66 \\
Scientific books in schools and universities & 43.8 \\
Are you ready to check the level of vitamin D in the body? & 23.6 \\
Yes & 28.2 \\
No & 55 \\
\hline
\end{tabular}

If you are diagnosed with a deficiency in the level of vitamin D, will you take vitamin D as a dietary supplement (tablets/

\begin{tabular}{lcc}
\hline Yes & 181 & 92.8 \\
No & 14 & 7.2 \\
\hline
\end{tabular}

the sources of vitamin D, on the contrary, about $14 \%$ of participants thought that the only source of vitamin $\mathrm{D}$ is sunlight. In this survey, $75.9 \%$ and $90.3 \%$ of the participants have known that vitamin D has a good effect on overall and bone health, respectively. In addition, vitamin $\mathrm{D}$ deficiency has been known to be related to muscle pain and other health issues (68.2\% and 50.8\%, respectively). The main source of vitamin $\mathrm{D}$ knowledge was from social media, friends, doctors on the internet and social sites $(53.3 \%, 49.7 \%$ and $47.2 \%$ respectively). The majority of the participants were ready to analyse the concentration of vitamin D in the body and will take vitamin $\mathrm{D}$ as a dietary supplement (tablets/injection) if they were diagnosed with a deficiency. There was no significant association that has been found between the knowledge of vitamin D and age, gender, education and social status.

\subsection{Sun exposure and practices about vitamin D}

The majority of participants (79\%) experienced sun exposure. About half of the participants (52\%) had sun exposure after $3 \mathrm{pm}$. However, $43.6 \%$ of the volunteers were only exposed early in the morning. Data in Table 3 indicates that $68.2 \%$ of the sample population thought 
Table 3. Sun exposure and practices about vitamin D

\begin{tabular}{|c|c|c|}
\hline Question & $\mathrm{N}$ & $\%$ \\
\hline \multicolumn{3}{|c|}{ Would you like to be exposed to the sun? } \\
\hline$\overline{\text { Yes }}$ & 154 & 79 \\
\hline No & 41 & 21 \\
\hline \multicolumn{3}{|c|}{ Do you usually protect yourself from the sun? } \\
\hline Yes & 40 & 20.5 \\
\hline No & 32 & 16.4 \\
\hline Some time & 123 & 63.1 \\
\hline \multicolumn{3}{|l|}{ Do you use sunscreen? } \\
\hline Yes & 45 & 23.1 \\
\hline No & 102 & 52.3 \\
\hline Some time & 48 & 24.6 \\
\hline \multicolumn{3}{|c|}{ If you a person who exposed to the sun, what is your usual time? } \\
\hline $6-8 \mathrm{am}$ & 85 & 43.6 \\
\hline $8-10 \mathrm{am}$ & 50 & 25.6 \\
\hline $10 \mathrm{am}-12 \mathrm{pm}$ & 39 & 20 \\
\hline after $3 \mathrm{pm}$ & 102 & 52.3 \\
\hline \multicolumn{3}{|c|}{ What parts of your body are exposed to sunlight? } \\
\hline Face & 141 & 72.3 \\
\hline Hands & 148 & 75.9 \\
\hline Feets & 90 & 46.2 \\
\hline Hands to elbows & 104 & 53.3 \\
\hline Legs & 43 & 22.1 \\
\hline Face and neck & 104 & 53.3 \\
\hline Other parts of the body & 15 & 7.7 \\
\hline \multicolumn{3}{|c|}{ Do you think your time in the sun is enough for you to get vitamin D? } \\
\hline Yes & 31 & 15.9 \\
\hline No & 133 & 68.2 \\
\hline I do not know & 31 & 15.9 \\
\hline \multicolumn{3}{|c|}{ Have you ever done a test on the level of vitamin $\mathrm{D}$ in the body? } \\
\hline$\overline{\text { Yes }}$ & 106 & 54.4 \\
\hline No & 89 & 45.6 \\
\hline \multicolumn{3}{|c|}{ What are the reasons for the analysis of vitamin D? } \\
\hline Doctor prescription & - & 31 \\
\hline Personal decision & - & 56 \\
\hline Other reason & - & 13 \\
\hline \multicolumn{3}{|c|}{ What was the result of the analysis? } \\
\hline Deficiency & 76 & 63.9 \\
\hline Insufficiency & 14 & 11.8 \\
\hline Sufficiency & 9 & 7.6 \\
\hline I do not know & 20 & 16.8 \\
\hline \multicolumn{3}{|c|}{ Did you take a vitamin D supplement after the analysis? } \\
\hline Yes & 89 & 73 \\
\hline No & 33 & 27 \\
\hline
\end{tabular}

Have you ever taken a vitamin D supplement or a group of nutritional supplements that contain vitamin D without having analysis?

\begin{tabular}{|c|c|c|}
\hline Yes & 82 & 42.1 \\
\hline No & 113 & 57.9 \\
\hline \multicolumn{3}{|c|}{ What are the reasons for taking these nutritional supplements that contain vitamin D? } \\
\hline An increase in health & 42 & 39.6 \\
\hline To raise immunity and prevent diseases & 47 & 44.3 \\
\hline Experiment & 8 & 7.5 \\
\hline To treat the pain you suffer from & 41 & 38.7 \\
\hline Other & 9 & 8.5 \\
\hline \multicolumn{3}{|l|}{ Have you taken vitamin D supplements with advice from ... } \\
\hline A doctor & 88 & 65.7 \\
\hline pharmacist & 15 & 11.2 \\
\hline Friend or relative & 27 & 20.1 \\
\hline The impact of social media & 9 & 6.7 \\
\hline After reading the health and medical awareness publications & 23 & 17.2 \\
\hline Other & 14 & 10.4 \\
\hline
\end{tabular}


Table 3 (Cont.). Sun exposure and practices about vitamin D

\begin{tabular}{lcc}
\hline Question & $\mathrm{N}$ & $\%$ \\
\hline Do you know how much vitamin D is needed from nutritional supplements? & 69 & 35.4 \\
\hline Yes & 126 & 64.6 \\
No & 66 & 67.3 \\
\hline What is the source or reference for you to know the necessary amount of vitamin D for the body? & 6.1 \\
\hline Doctor or pharmacist & 18 & 18.4 \\
Friends or relatives & 22 & 22.4 \\
Publications Health and Medical Awareness & & 39 \\
Other & 76 \\
\hline Do you know what is the adequate level of vitamin D in the body? & 119 & 61 \\
\hline Yes & 2 & 2.2 \\
No & 11 & 12.1 \\
\hline What is the adequate level of Vitamin D in the body? & 31.9 \\
\hline$<10 \mathrm{ng} / \mathrm{mL}$ & 29 & 53.8 \\
10-30 ng/mL & 49 & \\
30-100 ng/mL & & 61.5 \\
$>100$ ng/mL & 120 \\
Do you know what foods are rich in vitamin D? & 28 & 14.4 \\
\hline Milk, dairy products & 9 & 4.6 \\
Red meat & 120 & 61.5 \\
Chicken & 60 & 30.8 \\
Fatty fish & 67 & 34.4 \\
Fruit & 40 \\
Vegetables & 78 & 40 \\
Baked goods & 4 & 2.1 \\
Legumes & 30 & 15.4 \\
Butter & 23 & 11.8 \\
Mushroom & 33 & 16.9 \\
\hline
\end{tabular}

that most parts of the body exposed to the sunlight is enough for them to cover their needs. Almost half of the participants have undergone a test of vitamin D level and about $64 \%$ of the participants suffered from vitamin D deficiency or insufficiency and $89 \%$ have been taking supplements after their test. On the other hand, 42.1\% have taken supplements without doing the vitamin D test, which was the main reason to raise immunity and prevent diseases, an increase in health and to treat the pain $44.3 \%, 39.6 \%$ and $38.7 \%$, respectively. In this survey, doctors were the most influenced of the participants who have taken the advice of vitamin D supplementation at $65.7 \%$, then friends and relatives at $20.1 \%$. $61 \%$ of participants did not know the adequate level of vitamin D in the body. Milk, dairy products, and fatty fish were reported to be rich in vitamin D.

\subsection{Awareness of vitamin D after COVID-19 pandemic}

About $35 \%$ of participants improved their knowledge and attitude about vitamin D after the COVID-19 pandemic. A high percentage of participants thought that vitamin $\mathrm{D}$ raises the body immunity against viral infection or improve immunity in general. Around $67.7 \%$ thought that vitamin D prevents or may aid in the resistance of respiratory infections such as COVID19. The COVID-19 pandemic has affected $23.6 \%$ of participants in their choice of food rich in vitamin D. Only $11.3 \%$ of participants have been diagnosed with COVID- $19,38 \%$ and $41.2 \%$ of them have been informed by doctors to take dietary supplements of vitamin D and increase their exposure to sunlight, respectively (Table 4).

\section{Discussion}

Vitamin D deficiency is a public health issue around the world (Wahl et al., 2012) even in a country with sunshine most of the year (Green et al., 2015; Santos et al., 2019). Knowledge, awareness and practices about vitamin D may differ between communities and populations. The present study is one of the first studies to examine these factors before and after the emergence of COVID-19 among adults living in the Qassim region.

The finding of this study showed that most of the participants were well-versed about vitamin D. While majority knew the right sources of vitamin $\mathrm{D}$ and its benefits for their general health and bones. About half of the participants in this study thought that vitamin D deficiency was related to health conditions such as heart diseases, diabetes, depression, high blood cholesterol, cancer, multiple sclerosis and asthma. Previously, published studies related to vitamin D deficiency and 
Table 4. Awareness of vitamin D after the emergence of COVID-19

\begin{tabular}{|c|c|c|}
\hline Question & $\mathrm{N}$ & $\%$ \\
\hline Before the emergence of COVID-19 & 183 & 93.8 \\
\hline After the emergence of COVID-19 & 6 & 3.1 \\
\hline Do not have knowledge & 6 & 3.1 \\
\hline \multicolumn{3}{|c|}{ Is the emergence of COVID-19 affected you by increasing your knowledge? } \\
\hline Yes & 69 & 35.4 \\
\hline No & 126 & 64.6 \\
\hline
\end{tabular}

Do you think there is a relationship between vitamin D and raising the body immunity against viral infection or for improving immunity in general?

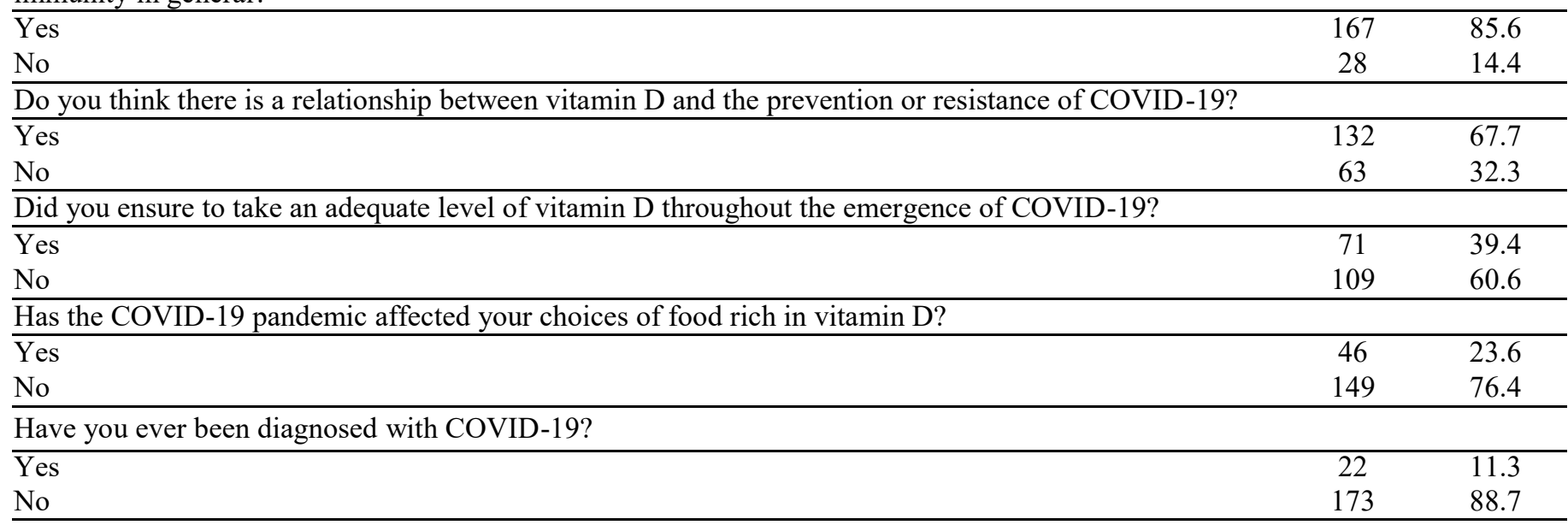

After being infected with COVID-19, have you been informed by doctors to take dietary supplements of vitamin D to raise

\begin{tabular}{|c|c|c|}
\hline Yes & 8 & 38 \\
\hline No & 13 & 62 \\
\hline \multicolumn{3}{|c|}{ After being infected with COVID-19, have you been informed by doctors to expose to sunlight to raise immunity? } \\
\hline Yes & 7 & 41.2 \\
\hline No & 10 & 58.8 \\
\hline
\end{tabular}

some of those health conditions were reviewed by Wang et al. (2017). The high knowledge of participants about vitamin D and their awareness of different sources was the highest from social media, friends, relatives, doctors on the internet and social site, which shows the large influence of social media within a population (Van de Belt et al., 2013).

Reflecting on the results, high knowledge and awareness about vitamin D, affected their readiness to analyse the vitamin D concentrations and treat vitamin D deficiency if they were diagnosed. Thus, this attitude can help the community to increase their health status and prevent any related health issues in the future. As the main source of vitamin D is sunlight (Holick, 2016), $80 \%$ of participants liked being exposed to the sun, few have reported to usually protect themselves from the sun, while others were exposed without sunscreen. The usual amount of time participants were exposed to sunlight was in the early morning from 6 to 8 am and after 3 pm, which is an efficient time to receive vitamin D from sunlight as it has been reported the perfect time to get vitamin $D$ from sunlight in the summer and winter was after 9:00 am to 10:30 am, 2:00 pm to 3:00 pm and 10:00 am to 2:00 pm, respectively (Al-Daghri et al., 2017).

The face, neck and hands were the body parts most exposed to sunlight in this survey which reflects the traditional clothes of this population in Qassim city. However, most participants thought the time exposure about 3 to 4 times a week was not enough to receive vitamin D and tended to expose $20 \%$ of their body (AlDaghri et al., 2017).

About half of the participants have undergone a test to check the vitamin D level in their bodies, which was a personal decision that reflects how educated the participants in this survey were about the importance of vitamin $D$. Their results of vitamin $D$ level were classified as a deficiency ( $64 \%)$, insufficiency $(\sim 12 \%)$, sufficiency $(\sim 7 \%)$ and unavailable results $(\sim 17 \%)$. The majority have taken vitamin D supplements after the analysis to increase its potency in the body (Institute of Medicine, 2011). However, around $42 \%$ of the participants taking the vitamin D supplement or group of nutritional supplements that contain vitamin D without having analyzed vitamin D were mostly interested in raising their immunity and prevent diseases and treating any ailments they suffer from. Most took the advice of doctors $(\sim 65 \%)$, friends and relatives $(\sim 20 \%)$ and after reading health and medical awareness $(\sim 17 \%)$. Whereas, the impact of social media was the lowest $(\sim 6 \%)$.

In this study, most of the participants do not know the adequate level of vitamin $\mathrm{D}$ in the body and around half of the participants selected $(>100 \mathrm{ng} / \mathrm{mL}$ or 250 
$\mathrm{nmol} / \mathrm{L}$ ) as the adequate level of vitamin $\mathrm{D}$. The recommended cut-off level of vitamin D by IOM, USA is $(20 \mathrm{ng} / \mathrm{mL}$ or $50 \mathrm{nmol} / \mathrm{L})$ for normal healthy people as the main basis of bone health whereas the range below $(30 \mathrm{ng} / \mathrm{mL}$ or $75 \mathrm{nmol} / \mathrm{L}$ ) of $25(\mathrm{OH}) \mathrm{D}$ concentration is considered vitamin D deficiency by Holick et al. (2011).

At the end of the year 2019, with the prominence of COVID-19 around the world, people are more worried about protecting themselves from the disease. As the awareness of vitamin D after the emergence of COVID19 was examined in this study, the results showed in the second part of this survey the majority of participants have been reading up about vitamin D (93.8\%) and a small percentage $(\sim 3 \%)$ of the participants were not as knowledgable about vitamin $\mathrm{D}$ after the emergence of COVID-19. However, ( $\sim 35 \%)$ of participants reported that the emergence of COVID-19 affected their needing to boost their immune systems.

The association between vitamin $\mathrm{D}$ and body immunity have been reported previously (Charoenngam and Holick, 2020) and in this study, the majority of participants $(85.6 \%)$ thought there is a relationship between vitamin $\mathrm{D}$ and rising the body immunity against viral infection or for improving immunity in general. This is due to reports published in this relation (Zemb, 2020). In this study, some participants around 39 and $23 \%$ ensured their intake of an adequate level of vitamin D throughout the emergence of COVID-19 and affected their choices of food rich in vitamin $\mathrm{D}$, which is a good practice among themselves

A few participants in this study have been diagnosed with COVID-19. It was interesting to note that some of the participants, after being infected with COVID-19 have been informed by doctors to take dietary supplements of vitamin D and to increase their exposure to sunlight to raise their immunity. This supports the importance of an adequate level of vitamin D (Charoenngam and Holick, 2020; Zemb, 2020).

\section{Conclusion}

A high level of knowledge and awareness about vitamin D in general adults living in the Qassim region were reported. There was no association between knowledge and awareness of vitamin D in age, gender, education or social status. The majority of participants under the current study were knowledgeable of the sources of vitamin D and were akin to the exposure of sunlight. The most effective time of exposure was found to be in the early morning and after $3 \mathrm{pm}$. The increasing awareness about vitamin D and its importance was collected from different sources where social media ranked the highest, before friends and relatives, and doctors on the internet and social sites. Participants increased their knowledge of vitamin $\mathrm{D}$ after the emergence of COVID-19, majority of participants thought that vitamin $\mathrm{D}$ raises the body immunity against viral infection and increases their resistance to COVID19.

\section{References}

Al-Daghri, N.M., Al-Saleh, Y., Aljohani, N., Sulimani, R., Al-Othman, A.M., Alfawaz, H., Fouda, M., AlAmri, F., Shahrani, A., Alharbi, M., Alshahrani, F., Tamimi, W., Sabico, S., Rizzoli, R. and Reginster, J.Y. (2017). Vitamin D status correction in Saudi Arabia: an experts' consensus under the auspices of the European Society for Clinical and Economic Aspects of Osteoporosis, Osteoarthritis, and Musculoskeletal Diseases (ESCEO). Archives of Osteoporosis, 12(1), 1-016-0295-y. https:// doi.org/10.1007/s11657-016-0295-y

Al-Daghri, N.M. (2018). Vitamin D in Saudi Arabia: Prevalence, distribution and disease associations. Journal of Steroid Biochemistry and Molecular Biology,175(1), 102-107. https://doi.org/10.1016/ j.jsbmb.2016.12.017

Bjorklund, G. (2016). Vitamin D Deficiency: A Global Health Problem, Peertechz Journal of Environmental Science and Toxicology, 1(1), 23-24. https:// doi.org/10.17352/pjest.000004

Charoenngam, N. and Holick, M.F. (2020), Immunologic Effects of Vitamin D on Human Health and Disease, Nutrients, 12(7), 2097. https://doi.org/10.3390/ nu12072097

Green, R.J., Samy, G., Miqdady, M.S., El-Hodhod, M., Akinyinka, O.O., Saleh, G., Haddad, J., Alsaedi, S.A., Mersal, A.Y., Edris, A. and Salah, M. (2015). Vitamin D deficiency and insufficiency in Africa and the Middle East, despite year-round sunny days, South African Medical Journal, 105(7), 603-605. https://doi.org/10.7196/SAMJnew.7785

Holick, M.F. (2016). Biological Effects of Sunlight, Ultraviolet Radiation, Visible Light, Infrared Radiation and Vitamin D for Health. Anticancer Research, 36(3), 1345-1356.

Holick, M.F. (2007). Vitamin D deficiency, The New England Journal of Medicine, 357(3), 266-281. https://doi.org/10.1056/NEJMra070553

Holick, M.F. (2004). Sunlight and vitamin D for bone health and prevention of autoimmune diseases, cancers, and cardiovascular disease. The American Journal of Clinical Nutrition, 80 (6), 1678S-88S. https://doi.org/10.1093/ajcn/80.6.1678S

Holick, M.F., Binkley, N.C., Bischoff-Ferrari, H.A., 
Gordon, C.M., Hanley, D.A., Heaney, R.P., Murad, M.H. and Weaver, C.M. (2011). Evaluation, treatment, and prevention of vitamin D deficiency: an Endocrine Society clinical practice guideline. The Journal of Clinical Endocrinology and Metabolism, 96(7), 1911-1930. https://doi.org/10.1210/jc.20110385

Institute of Medicine. (2011). Dietary reference intakes for calcium and vitamin D. Washington, DC, USA: The National Academies Press.

Jeffery, L.E., Qureshi, O.S., Gardner, D., Hou, T.Z., Briggs, Z., Soskic, B., Baker, J., Raza, K. and Sansom, D.M. (2015). Vitamin D Antagonises the Suppressive Effect of Inflammatory Cytokines on CTLA-4 Expression and Regulatory Function, PloS one, 10(7), e0131539. https://doi.org/10.1371/ journal.pone. 0131539

Kelishadi, R., Ardalan, G., Motlagh, M.E., Shariatinejad, K., Heshmat, R., Poursafa, P., Fakhri, M., Tajadini, M. and Taslimi, M. (2014). National report on the association of serum vitamin $\mathrm{D}$ with cardiometabolic risk factors in the pediatric population of the Middle East and North Africa (MENA): the CASPIAN-III Study. Nutrition, 30(1), 33-38. https:// doi.org/10.1016/j.nut.2013.05.018

Moreira, T.S. and Hamadeh, M.J. (2010). The role of vitamin $\mathrm{D}$ deficiency in the pathogenesis of type 2 diabetes mellitus. e-SPEN, the European e-Journal of Clinical Nutrition and Metabolism, 5(4), e155e165. https://doi.org/10.1016/j.eclnm.2010.05.001

Prietl, B., Treiber, G., Pieber, T.R. and Amrein, K. (2013). Vitamin D and immune function. Nutrients, 5(7) 2502-2521. https://doi.org/10.3390/nu5072502

Santos, M.P., Carvalho, G.Q., Santos D.B. and Oliveira A.M. (2019). Influence of vitamin D serum concentration, prenatal care and social determinants on birth weight: a northeastern Brazilian cohort study. British Journal of Nutrition, 122(3), 284-292. https://doi.org/10.1017/S0007114519001004

Van de Belt, T.H., Engelen, L.J., Berben, S.A., Teerenstra, S., Samsom, M. and Schoonhoven, L. (2013). Internet and social media for health-related information and communication in health care: preferences of the Dutch general population. Journal of Medical Internet Research, 15(10), e220. https:// doi.org/10.2196/jmir.2607

Wahl, D.A., Cooper, C., Ebeling, P.R., Eggersdorfer, M., Hilger, J., Hoffmann, K., Josse, R., Kanis, J.A., Mithal, A., Pierroz, D.D., Stenmark, J., Stöcklin, E. and Dawson-Hughes, B. (2012). A global representation of vitamin D status in healthy populations. Archives of Osteoporosis, 7, 155-172. https://doi.org/10.1007/s11657-012-0093-0
Wang, H., Chen, W., Li, D., Yin, X., Zhang, X., Olsen, N. and Zheng, S.G. (2017). Vitamin D and Chronic Diseases. Aging and Disease, 8(3), 346-353. https:// doi.org/10.14336/AD.2016.1021

Zemb, P., Bergman, P., Camargo, C.A., Jr, Cavalier, E., Cormier, C., Courbebaisse, M., Hollis, B., Joulia, F., Minisola, S., Pilz, S., Pludowski, P., Schmitt, F., Zdrenghea, M. and Souberbielle, J.C. (2020). Vitamin D deficiency and the COVID-19 pandemic. Journal of Global Antimicrobial Resistance, 22, 133134. https://doi.org/10.1016/j.jgar.2020.05.006 